\title{
FACTORS ASSOCIATS ALS TIPUS DE CURES DOMICILIÁRIES DE LES PERSONES EN SITUACIÓ DE DEPENDÉNCIA FUNCIONAL A BARCELONA
}

\begin{abstract}
ALBERT JULIÀ Institut d'Estudis Regionals i Metropolitans de Barcelona Universitat de Barcelona. Departament de Sociologia ajulia@ext.bcn.cat
\end{abstract}

RESUM: Les cures de les persones en situació de dependència funcional sovint són font de dificultats i desigualtats en les societats conegudes com a familistes. L'objectiu d'aquest article és identificar els perfils de les cuidadores i cuidadors de les persones en situació de dependència funcional, així com quines són les característiques que fan augmentar la probabilitat que rebin diferents tipus de cures domiciliàries. Per dur a terme aquesta anàlisi s'ha utilitzat la base de dades de l'Enquesta de Persones en Situació de Dependència Funcional (EPSD) realitzada el 2018 a la ciutat de Barcelona. Les dades mostren que hi ha una feminització generalitzada dels perfils professionals del personal cuidador (ja sigui d’àmbit públic o privat), així com en l'àmbit familiar, especialment quan es tracta de la persona cuidadora principal. Les Ilars amb ingressos elevats tenen una probabilitat més alta d'utilitzar serveis de cura de pagament, i les persones que viuen soles tenen menys probabilitat de rebre ajuda familiar i més de rebre ajudes per part dels serveis de l'Ajuntament. Els resultats mostren la necessitat d'intensificar les polítiques de cures, en especial en les llars amb menys recursos, en les que hi viuen persones amb 
dependència soles, i en les que es té com a principal persona cuidadora un familiar d'edat avançada.

PARAUleS CLAU: Dependència funcional; persones grans; desigualtats.

ABSTRACT: Functional dependence caregiving is often a source of difficulties and inequalities in familistic societies. The aim of this study is two-fold: to identify the profile of caregivers of functionally dependent individuals, and to analyse which characteristics increase the likelihood of receiving different types of domestic care. These analyses are carried out using the database of the Survey of People in a Situation of Functional Dependency 2018 (EPSD) from the city of Barcelona. The data shows that most caregivers are women, especially in the case of the main caregiver, and that this is the case in both the family and professional ambits and in the public and private sectors. High-income households are more likely to use paid care services, and people living alone are less likely to receive family care and more likely to receive care from local authority services. The results show the need to intensify public care policies, especially for low-income households, those who live alone, and those who have an elderly family member as their main caregiver.

KEYWORDS: Dependency; the elderly; inequalities. 


\section{Introducció}

Un dels grans reptes que tenen les societats avançades és la gestió de la creixent proporció de persones en situació de dependència funcional (en endavant SDF). De forma convergent als diferents països europeus, cada cop hi ha una major proporció de població amb edats avançades, el que fa que hi hagi una major probabilitat de tenir més persones que necessiten ajuda per poder desenvolupar les seves tasques quotidianes o amb necessitats de cura. Aquest és un dels grans reptes per als estats del benestar del segle xxi. Però no tots els models d'estat del benestar plantegen les mateixes receptes per fer-hi front. Els països amb models socialdemòcrates (o escandinaus) es caracteritzen per desenvolupar un sistema ampli i de gran cobertura de polítiques públiques que facilitin serveis i ajudes econòmiques perquè les necessitats de cura de les persones en SDF no hagin de recaure en les persones pròximes o familiars (Daly i Lewis, 2000). Aquests països també es caracteritzen per tenir una legislació més laxa pel que fa a les obligacions familiars intergeneracionals, així com una disposició de l'opinió pública que les funcions de cura hagin de recaure en major mesura a l'Estat que no pas als membres de la família de la persona en SDF. Per contra, en els estats del benestar de tipus conservadors, i especialment els mediterranis, ens trobem que els sistemes de polítiques públiques orientats a cobrir les necessitats de les persones en SDF són menys ambiciosos i d'escassa cobertura. En aquests països l'Estat no cobreix tant la funció de cura de les persones en SDF com ho farien les famílies (Calzada i Brooks, 2013). En aquestes societats les famílies són les que solen encarregar-se d'aquestes tasques, ja sigui contractant o pagant el servei de cura (mitjançant el mercat formal i/o informal), o que els propis membres de la família desenvolupin les tasques d'atenció i cura de forma intensa o complementària a altres perfils. Entre aquest segon grup de països es troba Espanya, que en nombrosos estudis està identificat com un model prominentment familista (León i Migliavacca, 2012; Dié Olmos, Fantova i Mota, 2014). Investigacions com la de Leitner (2003) o Platenga (2004) assenyalen Espanya com un model d'estat del benestar caracteritzat per una xarxa dèbil de serveis socials i 
de transferències econòmiques en la cura de les persones, el que fa que recaigui en gran mesura aquesta funció en els membres de la família.

El desenvolupament de les polítiques o dels models d'estat del benestar sovint va en consonància a les expectatives, orientacions i valors dels seus ciutadans. Alguns estudis mostren que la població espanyola manté una concepció familista cap a la cura de les persones grans i/o dependents. Per exemple, les darreres dades que proporcionen els estudis del Centre d'Investigacions Sociològiques (CIS), sobre les actituds i orientacions dels espanyols envers qui s'hauria de fer càrrec de les persones grans dependents que no poden dur a terme activitats bàsiques de la vida quotidiana sense ajuda, són molt illustratives (CIS, estudi núm. 3009, 2014). Segons aquest estudi, la meitat dels enquestats creuen que la millor opció és que les persones en SDF visquin amb algun familiar (53,7\%), mentre que aproximadament una cinquena part veuen com a millor opció que resideixin en un centre o residència, i una altra cinquena part que visquin amb una persona cuidadora remunerada. Aquestes dades pràcticament no varien significativament segons l'edat o el sexe de l'entrevistat. Tot i així, cal puntualitzar que en aquest estudi sí que varien aquests percentatges quan es pregunten per si fos el mateix entrevistat la persona en SDF. En aquest sentit, la proporció de persones que indica que l'haurien de cuidar membres de la seva família es redueix fins al 28,5\%. Aquesta diferència de les dades pot ser que demostri certa dissonància entre les orientacions cap a la cura de les persones de més edat i en SDF. És plausible que, per un costat, una gran proporció de persones mantinguin postures de caire tradicional sobre la cura de les persones de més edat o en SDF i que, a la vegada, entenguin que aquestes ajudes suposen una càrrega important, que condiciona la vida de les persones cuidadores i que la desitgen en menor mesura si un mateix és la persona que necessita aquestes cures. Sigui com sigui, el cas és que a Espanya la població segueix tenint unes orientacions més familistes que en països del nostre entorn. Mostra d'això són les dades de l'European Values Survey (2008) que mostren que el 90,5\% de la població espanyola està d'acord o molt d'acord que el deure dels fills/es és cuidar els seus progenitors malalts, mentre que en països de caire socialdemòcrata, com Dinamarca, el percentatge és del $25 \%$. 
L'elecció de qui es fa càrrec de l'atenció de les persones en SDF és un fenomen social complex i dinàmic en la qual intervenen factors molt diversos (Hillcoat-Nalletamby, 2019). Les persones dependents poden ser ateses fora de les seves Ilars (residències o centres de dia) o en les seves Ilars per familiars, per personal remunerat de manera formal o informal, per personal dels serveis públics, així com per altres persones cuidadores informals sense vincles familiars (com amics o veïns). Com ja s'ha comentat, la tria d'una o l'altra estratègia de cura ve condicionada per múltiples elements, i sovint les diferents formes de cura coexisteixen per una mateixa persona en SFD.

L'objectiu d'aquesta recerca és identificar i analitzar les diferències en les estratègies de cura en les persones en SDF, i veure quins són els perfils que principalment es fan càrrec d'aquestes tasques de cura a la ciutat de Barcelona. Es tracta de veure quins són els factors que estan associats que uns perfils de persones tinguin major probabilitat de fer-se càrrec de les persones en SDF. En la part final d'aquest article s'inclou un apartat de conclusions on es discuteixen alguns dels resultats d'aquesta recerca i la implicació de les polítiques públiques que se'n deriva.

\section{Factors associats als tipus de cures}

Les persones en SDF poden ser ateses en les seves llars per familiars, per personal remunerat de manera formal o informal, per personal dels serveis públics - ateses les polítiques i serveis públics oferts en cada territori-, així com per altres persones cuidadores informals sense vincles familiars com són els amics o els veïns (Barker, 2002).

Tot i la importància de les orientacions i les preferències que té la població, no s'ha de menystenir la importància de la disponibilitat de recursos econòmics i relacionals per entendre les diferents formes de cura de les persones en SDF que s'acaben adoptant. Les principals línies de recerca sobre els factors que determinen el tipus d'ajudes o cures que reben les persones majors dependents solen centrar-se en les característiques dels dependents, de les seves Ilars, de les preferències i disponibilitat dels seus familiars, i dels recursos que disposen, tant econòmics com humans (Fernández-Carro, 2014). Tenir més o menys recursos econòmics per poder pagar residències o personal cuidador formal o informal pot condicionar en gran mesura la presa de decisions 
en el moment de gestionar les tasques de cura (Becker, 1993; Saraceno, 2010). Segons l'estudi d'Ayuso et alii (2010), els ingressos de la llar de les persones en SDF i dels seus familiars condiciona la probabilitat que siguin els familiars o personal extern qui se'n faci càrrec. Al mateix temps, Sarasa i Billingsley (2008) i Groenou et alii (2006) apunten que, independentment de la tipologia de règim de benestar del país, com més petit és l'estatus socioeconòmic de les persones en SDF major és la possibilitat que els fills (especialment les filles) dediquin més temps en la cura informal dels seus progenitors.

Més enllà de la influència dels recursos econòmics per determinar el tipus d'ajudes que reben les persones en SDF, hi ha altres aspectes que s'han identificat en anteriors estudis com el tipus de dependència, l'edat, el sexe (Ganong i Coleman, 1999; Adams et alii, 2002), l'ètnia (Adams et alii, 2002) o les persones amb les quals convisqui (Rogero, 2009). La presència o l'absència de xarxes de suport també influeixen en l'elecció de diferents estratègies de cura. La manca d'aquestes xarxes, com les persones que viuen soles i/o tenen pocs o cap familiar proper en contacte, poden tenir una probabilitat menor de rebre cura d'algun familiar i dependre en major mesura dels serveis que presti l'Administració pública o del que pugui assumir econòmicament en el mercat formal o informal (Rogero, 2009).

Les formes de cura també poden venir influenciades per les característiques de les persones en SDF. Les necessitats de les persones en SDF poden variar segons el grau i el tipus de dependència (Adams et alii, 2002). Les estratègies de cures resultants poden ser molt dispars ateses aquestes característiques. Les persones amb graus més elevats de dependència solen necessitar major suport i més constant per la majoria de tasques quotidianes del dia a dia. Això fa que les tasques domiciliàries públiques siguin menys atractives i es pugui tendir a recórrer al mercat formal o informal i a membres familiars en aquests perfils.

Segons la literatura revisada, hauríem d'esperar que: 1) en les llars de rendes més altes a Barcelona siguin on trobem major probabilitat d'ús de les cures remunerades $i$, en conseqüència, una menor probabilitat de trobar ajudes domiciliàries de serveis públics o de familiars; 2) les persones que viuen soles tenen major probabilitat de rebre ajudes de familiars i major probabilitat de rebre'n de serveis públics o de forma remunerada; i 3) les persones en SDF que tenen nivells més severs de dependència tenen més probabilitat de rebre ajudes de familiars o de cuidadors/es de pagament. 


\section{Metodologia}

Per realitzar aquesta recerca s'utilitzen les dades provinents de l'Enquesta de Persones en Situació de Dependència Funcional 2018 de Barcelona (en endavant EPSD). Es tracta d'una enquesta dirigida a persones en situació de dependència reconeguda. La informació està extreta mitjançant entrevistes presencials amb la metodologia CAPI (Computer-Assisted Personal Interviewing). La mostra està composta per 613 observacions, representatives dels barris amb rendes baixes (seleccionats de quatre barris amb un nivell mitjà de 84,3 punts de l'índex RFD') i barris de rendes altes (seleccionats de cinc barris amb un nivell de RFD mitjà de 199 punts). La mostra es va obtenir mitjançant una selecció aleatòria de persones en SDF dintre dels dos grups de barris seleccionats de Barcelona. Com es pot observar a la taula 1 , la mostra de persones en SDF està principalment formada per persones de més de 64 anys $(83,7 \%)$, i amb una alta representació de dones $(70,6 \%)$. Les persones en SDF poden ser usuàries del Servei d'Atenció Domiciliària (SAD) que ofereix l'Administració local, i/o persones que perceben una prestació econòmica en comptes del servei (reconeguda segons la llei 39/2006) per poder fer front a les despeses de cura (Cuidador No Professional: CNP). Tant la prestació econòmica com el SAD no tenen establerta cap diferenciació per motius econòmics. És a dir, la situació financera dels dependents no determina la quantitat ni un copagament del servei. El funcionament de Barcelona del SAD no és comú en altres territoris o comunitats autònomes. A partir de la Llei de promoció de l'autonomia personal i atenció a les persones en situació de dependència (LAPAD), es van establir una sèrie de barems (que es van modificar amb el Reial Decret-Llei 20/2012) en els quals s'establia la proporció que s'hauria de contribuir econòmicament per part dels beneficiaris que podrien ser modificades segons les comunitats autònomes. En el cas de la ciutat de Barcelona, i a diferència del que sol passar a la majoria de territoris d'Espanya (Martínez-Buján, 2014), està establert no realitzar cap copagament, el que pot explicar l'alta demanda del servei de SAD envers del CNP

1 La Renda Familiar Disponible és un indicador que calcula anualment l'Ajuntament de Barcelona per dirimir les diferències de renda dels barris de la ciutat i el seu nivell de desigualtat (Calvo, 2007). Els barris seleccionats amb les rendes baixes són: Sant Antoni, La Marina de Port, Vilapicina i la Torre Llobeta, i el Poblenou. Amb les rendes altes: Pedralbes, Sarrià, les Tres Torres, Sant Cervasi-Calvany, i el Putxet i Farró. 
(Del Pozo i Escribano, 2013; Del Pozo et alii, 2016). Pel que fa a la quantia de la prestació econòmica, en el cas dels CNP, vindria determinat pel grau de dependència concedida per l'Administració pública.

La mostra es compon d'un 39,6\% de persones en grau I de dependència funcional, un $34,6 \%$ de grau II, i un 14\% de grau III (el grau més intens de dependència). La resta de mostra $(11,4 \%)$ principalment està composta per persones que reben el servei de $\mathrm{SAD}$ o la prestació (CNP) perquè des de l'Administració local s'ha determinat que estan en SDF però encara estan a l'espera de rebre l'assignació del grau de dependència. Un altre element a tenir en compte de la mostra és que una de cada quatre de les persones en SDF viuen soles, i, per tant, depenen exclusivament de les ajudes de les persones no convivents, dels SAD o de serveis remunerats.

Taula 1. Dades descriptives de la mostra de persones en SDF ( $\mathrm{N}=613)$

\begin{tabular}{lccccc} 
& N & $(\%)$ & & N & $(\%)$ \\
\hline Tipologia barri & & & Edat & & \\
Rendes baixes & 406 & $(66,2)$ & $<18$ anys & 14 & $(2,3)$ \\
Rendes altes & 207 & $(33,8)$ & $18-34$ & 13 & $(2,1)$ \\
Tipus d'atenció & & & $35-64$ & 73 & $(11,2)$ \\
SAD & 313 & $(51,1)$ & $65-80$ & 128 & $(20,9)$ \\
CNP & 300 & $(48,9)$ & 81 i més anys & 385 & $(62,8)$ \\
Grau de Dependència & & & Nacionalitat de la persona en SDF & \\
Grau I & 243 & $(39,6)$ & Espanyola & 605 & $(98,7)$ \\
Grau II & 212 & $(34,6)$ & Estrangera & 8 & $(1,3)$ \\
Grau III & 86 & $(14,0)$ & Nombre de convivents a la Ilar & & \\
Sense reconeixement/NC & 72 & $(11,8)$ & Unipersonal & 154 & $(25,1)$ \\
Sexe de la persona en SDF & & & Dues persones & 267 & $(43,6)$ \\
Home & 180 & $(29,4)$ & Tres persones & 112 & $(18,3)$ \\
Dona & 433 & $(70,6)$ & Quatre o més & 80 & $(13,1)$ \\
\hline
\end{tabular}

SDF= Situació de Dependència Funcional; $S A D=$ Servei Atenció Domiciliària; CNP=Cuidador/a No Professional 
En el present article no només es tenen en compte les persones en SDF, sinó també els perfils dels seus cuidadors/es. La majoria de persones en SDF no només reben ajuda d'una persona cuidadora o d'un servei, sinó que sol rebre una varietat confluent d'ajudes. Segons les dades de l'ESPD les persones dependents reben una mitjana d'ajudes de 2,2 persones o serveis diferents a domicili. Per aquest motiu algunes de les dades que es presenten en aquest estudi tenen una mostra més elevada, ja que es té en consideració el nombre total de persones que ajuden a les persones en SDF.

L'EPSD està realitzada a les persones en SDF. D'aquesta enquesta van poder respondre principalment les persones en SDF, però en alguns casos, especialment persones amb graus més alts de dependència, els enquestats necessiten ajuda per respondre d'algun familiar o del seu principal cuidador (que també sol ser algun membre familiar) o en un percentatge menor respon exclusivament el cuidador (en alguns casos de grau III). Així, el 68\% dels qüestionaris els va respondre exclusivament la persona en SDF i el 32\% van necessitar algun suport o directament ho va fer un familiar o cuidador/a.

El nombre de cuidadors/es de la mostra és d'un total de 1.376 individus, que poden ser familiars, personal remunerat formal o informal, personal del SAD i altres tipus d'ajuts domiciliaris. D'aquesta mostra el $45,2 \%$ són familiars, el 29,8\% del SAD, l'11,1\% es troben remunerades de forma formal, ${ }^{2}$ el $8 \%$ cuidadores remunerades informals (amb remuneració sense contracte), 4,4\% amistats o veïns/es sense remunerar, i 1,5\% altres perfils. S'ha d'assenyalar que quan s'analitza la mostra dels perfils de cuidadors (que prové de la mostra de persones en SDF) ens podem trobar amb casos duplicats. És probable que en persones cuidadores remunerades $i$, especialment, del servei $S A D$, una mateixa persona cuidi a més d'una persona en SDF de la mostra. Les dades no permeten identificar els casos duplicats de cuidadors remunerats o els de serveis públics, però no es preveu que variïn en gran mesura els resultats descriptius dels tipus de perfils.

2 En la categoria de persones cuidadores remunerades formals s'agrupen: a) el personal contractat/pagat amb ajuda de les prestacions econòmiques de la Llei de dependència; $b$ ) el personal contractat/pagat sense ajuda de les prestacions econòmiques de la Llei de dependència; $c$ ) personal d'empreses privades de serveis socials i/o sanitaris. 
Per analitzar els perfils de les persones que cuiden s'ha realitzat una anàlisi descriptiva sobre quines són les característiques sociodemogràfiques (sexe, edat i país de procedència) dels cuidadors/es que es relacionen amb les diferents tipologies de cura. Tots els resultats descriptius mostren Chi quadrades $<0,05$, el que indica que les diferències entre les categories analitzades de cada variable són estadísticament significatives. En un segon nivell d'anàlisi, tenint en compte la mostra de persones en SDF, s'inclouen tres models de regressió logística per dirimir quines són les característiques dels SDF i de les seves llars que fan que hi hagi més probabilitat que rebin algun d'aquests tipus de cures: a) cures familiars; b) cures del $S A D, i c$ ) cures remunerades (sense diferenciar si són de pagament formal o informal). En aquest sentit, s'ha de tenir en compte que es descarta realitzar una regressió multinomial degut que les categories de la variable dependent no serien mútuament excloents. Com ja s'ha assenyalat anteriorment, les persones en SDF solen tenir més d'una persona o servei de cura i sovint són de tipologia combinada. Segons les dades de l'EPSD, aproximadament el 50\% combinen més d'un tipus de cura. Així doncs, el $66,2 \%$ reben ajuda d'un o més familiars, el 44,5\% reben del $S A D$, i el $37,7 \%$ reben ajuda d'alguna persona o servei de pagament (remunerat). Cada una d'aquestes tipologies suposen les variables dependents dicotòmiques de cada un dels tres models.

Pels models de regressió logística s'han introduït diferents variables independents. Pel que fa al nivell de característiques individuals s'han inclòs el grau de dependència (quatre categories: «Grau I» com a referència, «Grau II», «Grau III» i «Pendent d'adjudicar»). Respecte a les característiques de la llar s'inclouen el nombre de persones amb qui conviu (tres categories: "sol/a" com a categoria de referència, «amb una altra persona», «amb dues o més persones») i els ingressos de la llar que s'introdueixen en quartils (el primer quartil, que són els ingressos més baixos, com el de referència). Segons l'estudi realitzat per Rogero (2009), les persones que estan en SDF que viuen soles tenen una menor probabilitat de rebre cures informals (principalment de familiars) que les que conviuen amb altres familiars. Segons altres estudis, també els ingressos incideixen en el tipus de cura que s'estableix, de tal forma que els que solen tenir més 
ingressos acaben tenint menys ajudes de familiars i tendeixen més a ajudes externes de pagament (Becker, 1993; Saraceno, 2010). En els tres models de regressió logística també s'inclouen com a variables de control el sexe («dona» com a categoria de referència) i l'edat de la persones en SDF (quatre categories: «< de 35 anys», «36 a 64», «65 a 80», i «81 o més» com a referència). En aquest sentit, alguns estudis apunten que les dones en SDF són les que tenen menys probabilitat de rebre cura informal (Katz et alii, 2000; Rogero, 2009).

\section{Resultats}

Les dades de l'EPSD mostren que hi ha una alta concentració de perfils de personal cuidador femení. El 77,1\% de les persones cuidadores són dones. Les dades mostren que les cures més professionalitzades són les que tenen una prevalença major de dones. Com es pot observar a la taula 2, tant el personal provinent de l'Administració pública com el que rep una remuneració formal o informal, el percentatge de dones supera el $90 \%$, mentre que en els perfils de veïns/amics se situaria pel 81\%, i en els familiars seria el que tindria una bretxa de gènere més reduïda (les dones representen el $57,6 \%$ de les persones cuidadores familiars). Pel que fa a l'edat de les persones cuidadores, també hi ha una clara diferència entre les que són familiars o les que provenen d'altres serveis públic o privats. Tant en els familiars com en amistats o veïns hi ha una proporció substancial de persones que s'encarreguen de tasques de cura i que tenen més de 64 anys. Així mateix, és especialment aclaparador que el 18,4\% de les persones cuidadores familiars tenen més de 80 anys. 
Taula 2. Perfils sociodemogràfics de les persones cuidadores segons el tipus de cuidador/a $(\mathrm{N}=1.376)$

\begin{tabular}{|l|c|c|c|c|c|c|c|c|c|}
\cline { 2 - 11 } \multicolumn{1}{l|}{} & \multicolumn{2}{c|}{ Sexe } & \multicolumn{2}{c|}{ Origen } & \multicolumn{4}{c|}{ Edat } \\
\cline { 2 - 11 } & Home & Dona & Espanya & $\begin{array}{c}\text { Fora } \\
\text { Espanya }\end{array}$ & $<30$ & $30-49$ & $50-64$ & $65-80$ & $810+$ \\
\hline Familiar & 42,4 & 57,6 & 96,3 & 3,7 & 7,8 & 16,6 & 34,2 & 22,9 & 18,4 \\
\hline $\begin{array}{l}\text { Persona de } \\
\text { serveis públics. } \\
\text { Ajuntament }\end{array}$ & 4,9 & 95,1 & 49,1 & 50,9 & 12,3 & 47,5 & 38,5 & 1,6 & 0,0 \\
\hline $\begin{array}{l}\text { Persona/servei } \\
\text { remunerada formal }\end{array}$ & 4,1 & 95,9 & 23,8 & 76,2 & 10,9 & 48,8 & 37,2 & 3,1 & 0,0 \\
\hline $\begin{array}{l}\text { Persona } \\
\text { remunerada } \\
\text { informal }\end{array}$ & 7,3 & 92,7 & 26,0 & 74,0 & 5,4 & 55,9 & 34,4 & 4,3 & 0,0 \\
\hline $\begin{array}{l}\text { Amic/amiga } \\
\text { Veí/veïna (no } \\
\text { remunerat) }\end{array}$ & 18,3 & 81,7 & 91,7 & 8,3 & 8,3 & 28,3 & 38,3 & 20,0 & 5,0 \\
\hline Altres & 21,4 & 78,6 & 80,0 & 20,0 & 20,0 & 30,0 & 30,0 & 20,0 & 0,0 \\
\hline
\end{tabular}

Si tenim en compte les dades sobre els perfils de les persones cuidadores segons l'origen, el 30,2\% de les persones cuidadores són nascudes fora d'Espanya. El percentatge és especialment destacat en les persones que treballen de forma remunerada (informal o no). Al voltant del $75 \%$ són nascudes fora d'Espanya, i en el cas del SAD, la relació seria força més equilibrada.

Com ja s'ha comentat amb anterioritat, les persones en SDF poden tenir més d'un cuidador/a. La càrrega de les persones cuidadores no sempre és la mateixa i és convenient tenir en compte qui és la persona que té majors càrregues, ja que algunes persones poden assumir tasques molt esporàdiques mentre d'altres hi poden estar dedicant la pràctica totalitat del dia. Segons les dades de l'ESPD, el 61,3\% de les persones cuidadores principals són familiars, el 15,8\% seria personal del SAD, 11,8\% personal remunerat formal i 8,4\% informal (amics/veïns i altres només arriben al $3,4 \%$ dels cuidadors/es principals). Així doncs, si tenim en compte quina és la persona que es declara com a principal cuidadora, veiem que la prevalença d'alguns perfils varia. Per exemple, la bretxa de gènere s'amplia quan es tenen en compte les persones cuidadores principals en el cas dels 
familiars. Tal com es pot observar en la taula 3, la diferència de gènere arriba a 31 punts percentuals quan es té en compte les característiques sociodemogràfiques del principal cuidador/a.

Taula 3. Perfils sociodemogràfics de les persones cuidadores principals segons tipologia de cuidador/a $(\mathrm{N}=613)$

\begin{tabular}{|l|c|c|c|c|c|c|c|c|c|}
\cline { 2 - 11 } \multicolumn{1}{c|}{} & \multicolumn{2}{c|}{ Sexe } & \multicolumn{2}{c|}{ Origen } & \multicolumn{3}{c|}{ Edat } \\
\cline { 2 - 11 } & Home & Dona & Espanya & $\begin{array}{c}\text { Fora } \\
\text { Espanya }\end{array}$ & $<30$ & $30-49$ & $50-64$ & $65-80$ & $810+$ \\
\hline Familiar & 30,7 & 69,3 & 95,4 & 4,6 & 1,5 & 11,9 & 35,3 & 30,4 & 21,0 \\
\hline $\begin{array}{l}\text { Persona de serveis } \\
\text { públics. Ajuntament }\end{array}$ & 5,9 & 94,1 & 66,7 & 33,3 & 9,5 & 34,9 & 50,8 & 4,8 & 0,0 \\
\hline $\begin{array}{l}\text { Persona/servei } \\
\text { remunerada formal }\end{array}$ & 0,0 & 100 & 12,3 & 87,7 & 18,5 & 38,9 & 38,9 & 3,7 & 0,0 \\
\hline $\begin{array}{l}\text { Persona remunerada } \\
\text { informal }\end{array}$ & 6,7 & 93,3 & 18,6 & 81,4 & 5,3 & 52,6 & 36,8 & 5,3 & 0,0 \\
\hline
\end{tabular}

Les tasques de cura poden esdevenir unes activitats que poden afectar la salut psicològica i física dels qui les porten a terme. Un dels elements que poden fer que la probabilitat que aquestes tasques afectin negativament és l'edat de les persones cuidadores. Com més edat tenen les persones cuidadores més exigents poden esdevenir aquestes tasques. Atenent aquesta situació, les dades assenyalen un percentatge gens menyspreable de persones que són les principals cuidadores tot i tenir una edat avançada. Una de cada cinc persones cuidadores familiars tenen més de 80 anys. Les persones d'edat avançada que són les cuidadores principals solen ser la parella de la persona major en SDF. El 81,2\% dels cuidadors principals de més de 80 anys són la parella de la persona en $\operatorname{SDF}(46,4 \%$ parella home i $34,8 \%$ parella dona). La resta es compon de mares $(11,6 \%)$ o pares $(1,4 \%)$ i germanes (7,2\%).

Més enllà d'aquest grup d'edat, les principals cuidadores familiars de persones en SDF solen ser les filles, que acostumen a ser més del doble que els fills (26,7\% i 10,6\% respectivament). Les parelles serien el segon rol 
familiar més freqüent, on trobaríem una bretxa de gènere no tan acusada com en altres rols familiars. En aquest sentit, les parelles dones representen el $20,1 \%$ de les principals cuidadores, i les parelles homes el 16,7\%. La resta de rols familiars més freqüents solen estar més representats per dones. En destaquen les mares (14,3\%), les germanes (4,6\%), altres familiars dones $(4,0)$ per sobre dels pares $(2,1)$, els germans $(0,6)$ i altres familiars homes $(0,6)$.

Els resultats mostrats fins aquest punt donen una visió de quina és la prevalença dels perfils de cura de les persones en SDF. El següent pas és veure quins factors s'associen al fet que les persones en SDF tinguin més o menys probabilitat de rebre ajudes de cuidadors familiars, remunerats o del SAD. En la taula 4 es poden veure els resultats dels tres models de regressió logística que mostren les diferents incidències de cada un dels factors considerats.

Segons els tres models de regressió, el model més predictiu és el de cuidador/a familiar, seguit del model que prediu tenir cuidadors/es procedents de l'Administració local i en menor mesura tenir ajudes mitjançant el pagament d'una persona cuidadora o servei domiciliari. En el model 1, destaca de forma molt significativa l'efecte de conviure amb altres persones. Les persones en SDF que conviuen amb altres familiars tenen una probabilitat molt més alta de rebre ajudes de cura per part d'aquesta, i aquesta probabilitat augmenta quan més convivents hi hagi a la llar. Segons els ingressos de la llar i el grau de dependència no s'observen diferències significatives en aquest model. Tanmateix, sí que s'observa que les persones en SDF de llars amb ingressos alts tenen major probabilitat de rebre ajuts remunerats ( $O R=2,79 ; \mathrm{p}<0,001$; model 3 ) i menys probabilitat de rebre ajust del $\mathrm{SAD}(\mathrm{OR}=0,46 ; \mathrm{p}<0,01$; model 2) que el quartil de menys ingressos.

El nombre de persones a la llar també influeix en la probabilitat de rebre $\mathrm{SAD}$. Les persones soles tenen una major probabilitat de rebre aquesta ajuda que les que conviuen amb una o més persones. Sembla que aquest servei és essencial per aquest tipus de persones. Per contra, el nombre de persones de convivència no sembla tenir una influència a tenir o no persones cuidadores remunerades un cop es controla per la resta de variables. 


\section{Taula 4. Regressió logística. Factors associats a tenir diferents tipus} de persones cuidadores segons les característiques de les persones en SDF i de la seva llar

\begin{tabular}{|c|c|c|c|c|c|c|}
\hline & \multicolumn{2}{|c|}{ Model 1: familiar } & \multicolumn{2}{|c|}{ Model 2: SAD } & \multicolumn{2}{|c|}{ Model 3: remunerat } \\
\hline & OR & $\mathrm{EE}$ & OR & $\mathrm{EE}$ & OR & $\mathrm{EE}$ \\
\hline \multicolumn{7}{|l|}{ Característiques individuals } \\
\hline \multicolumn{7}{|l|}{ Sexe (ref. Dona) } \\
\hline Home & 1,58 & $(0,29)$ & 0,85 & $(0,23)$ & 0,76 & $(0,22)$ \\
\hline \multicolumn{7}{|l|}{ Edat (ref. > 80) } \\
\hline$<35$ & 6,63 & $(1,37)$ & 0,27 & $(0,81)$ & 0,00 & $(--)$ \\
\hline $35-64$ & 1,50 & $(0,43)$ & $0,32^{* * *}$ & $(0,35)$ & $0,18^{* * *}$ & $(0,38)$ \\
\hline $65-80$ & $2,39^{*}$ & $(0,35)$ & $0,58^{*}$ & $(0,25)$ & 0,71 & $(0,23)$ \\
\hline \multicolumn{7}{|c|}{ Grau de dependència (ref. Grau I) } \\
\hline Grau II & 1,48 & $(0,30)$ & $0,64^{*}$ & $(0,22)$ & 1,34 & $(0,22)$ \\
\hline Grau III & 0,76 & $(0,38)$ & $0,39^{\text {**:* }}$ & $(0,34)$ & $3,95^{5 * \ldots *}$ & $(0,32)$ \\
\hline Pendent d'adjudicar & 0,64 & $(0,42)$ & $4,70^{* * * * *}$ & $(0,40)$ & $0,52 \dagger$ & $(0,34)$ \\
\hline \multicolumn{7}{|l|}{ Característiques de la llar } \\
\hline \multicolumn{7}{|l|}{ Convivència (ref. sol) } \\
\hline Amb una persona & $35,80^{* \ldots+\%}$ & $(0,35)$ & $0,43^{* * * \pi}$ & $(0,26)$ & 1,03 & $(0,25)$ \\
\hline Amb dos o més & 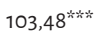 & $(0,43)$ & 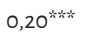 & $(0,29)$ & 0,98 & $(0,28)$ \\
\hline \multicolumn{7}{|c|}{ Ingressos de la llar (ref. Quartil 1) } \\
\hline Quartil 2 & 1,25 & $(0,36)$ & 0,88 & $(0,28)$ & 0,65 & $(0,28)$ \\
\hline Quartil 3 & 1,43 & $(0,35)$ & 0,73 & $(0,27)$ & 1,17 & $(0,27)$ \\
\hline Quartil 4 & 1,36 & $(0,37)$ & $0,46^{\text {\%* }}$ & $(0,29)$ & $2,79^{* * \ldots * *}$ & $(0,28)$ \\
\hline Constant & $0,06^{* * * *}$ & $(0,41)$ & $4,07^{* * *}$ & $(0,29)$ & $0,59 \dagger$ & $(0,27)$ \\
\hline $\mathrm{N}$ & 613 & & 613 & & 613 & \\
\hline Nagelkerke $\mathrm{R}^{2}$ & 0,59 & & 0,35 & & 0,24 & \\
\hline Log likelihood & 413,09 & & 639,94 & & 670,20 & \\
\hline \multicolumn{7}{|c|}{ Nota: OR=Odds Ratio; EE= Error Estàndard; --Valor elevat degut a pocs casos. } \\
\hline vells de sianificació. & $\because p<0.0$ & & & & & \\
\hline
\end{tabular}


Pel que fa al grau de dependència, les dades indiquen que, a igualtat de condicions, les persones en SDF de grau II o III tenen menor probabilitat de rebre ajuts del SAD que les de grau I. En canvi, les persones de grau III tenen fins a quatre cops més probabilitat de rebre ajusts remunerats que les persones amb grau I. Els resultats semblen indicar la tendència que les persones amb menor grau de dependència fan més ús del servei del SAD i els que tenen majors dificultats i demanden un major nivell d'assistència recorren a serveis de pagament amb independència del seu nivell d'ingressos.

\section{Conclusions}

Les cures de les persones en SDF poden esdevenir una càrrega sovint difícil de gestionar si no es tenen els recursos econòmics o humans per desenvolupar-les. Inclús disposar de familiars o persones properes que ajudin en aquestes tasques pot arribar a tenir certs impactes negatius per a les persones cuidadores, ja que sovint requereixen esforços físics i mentals, així com una disponibilitat que pot suposar un cost d'oportunitat o malmetre les expectatives vitals. Tot i que algunes recerques mostren que hi poden haver certs efectes positius en les persones cuidadores (Nolan et. al, 1996), cal dir que la majoria d'evidències assenyalen que existeixen potencials efectes negatius quan es realitzen aquestes activitats (Larrañaga et alii, 2008). Sense anar més lluny, les dades de l'EPSD mostren que hi ha un percentatge substancial de persones d'edat avançada que no només ajuden a les persones en SDF, sinó que esdevenen les principals cuidadores (essencialment de la seva parella). Per a aquests perfils les tasques de cura poden considerar-se tot un repte que pot acabar tenint repercussions en el seu benestar físic i mental.

Tanmateix, el context en què s'analitzen aquestes dades és en una societat amb un alt grau de familisme (especialment en les persones de més edat), la qual cosa suposa que una gran part d'aquestes persones rebutgin o prefereixin no escollir altres opcions de cura que no sigui a través dels familiars. Tal com assenyalen Eichler i Pfau-Effinger (2009), és possible que les persones grans i els seus familiars no utilitzin tots els serveis o polítiques públiques d'atenció a les persones en SDF disponibles perquè 
poden preferir mantenir formes d'atenció tradicionals basades en el suport familiar. Segons aquests autors, el motiu principal d'aquestes decisions és que el comportament de les persones (especialment si són d'edat més avançada) i de les seves famílies sol estar més alineat amb els valors i orientacions d'atenció tradicionals, en què es prioritza el suport mutu entre els cònjuges i els seus descendents. Els individus valoren que hi ha certes diferències entre el tipus d'atenció que pot proporcionar un servei públic i la que pot oferir un familiar, la qual cosa fa que sovint es percebi com a més atractiva per a les persones en SDF i per als seus familiars l'opció de cures de familiars.

Per altra banda, altres estudis també mostren que si les persones en SDF estan casades o viuen en parella solen tenir més probabilitat de rebre cures que ofereixi l'Administració pública que els que no viuen en parella, atès que els cònjuges actuen com a connectors entre la persona gran i el sistema públic (Rogero, 2009). En aquest sentit, les dades de l'EPSD mostren de forma clara que les persones que viuen soles a Barcelona són les que tenen més probabilitat d'utilitzar el SAD, i que com més persones conviuen en la llar menys probabilitat hi ha que s'utilitzi aquest servei i més que s'utilitzin les ajudes dels familiars. Així doncs, els resultats reforcen l'argument familista de les cures a la ciutat de Barcelona, en què el nivell de benestar de les persones depèn en gran mesura de la xarxa familiar que tingui cada individu (Julià i Rojas, 2019). En les llars que hi hagi disponibilitat de recursos familiars per les cures de les persones en SDF aquesta seria l'estratègia més probable amb independència dels recursos econòmics que es tinguin. Al mateix temps, en les llars amb ingressos més alts la probabilitat que també s'utilitzi una atenció remunerada és major que en llars amb ingressos baixos. El que no trobem en les dades són diferències estadísticament significatives entre els diferents nivells d'ingressos de la llar i que variï la probabilitat que sigui un familiar el cuidador. Aquestes dades reforçarien l'argument familista de les orientacions i creences de la població, en el sentit que, independentment del perfil econòmic de la llar, els familiars acaben assumint part de la funció de les cures domiciliàries. 
Les dades també mostren que el grau de dependència influeix en aquesta presa de decisions. Per les persones amb grau III, que requereixen una major atenció de temps i d'exigència de les tasques, hi ha una probabilitat més baixa que les persones utilitzin el SAD (que sol proporcionar una atenció reduïda d'hores setmanals) i tendeixin molt més a buscar una atenció remunerada que segurament pugui abastar més temps d'atenció.

Un altre dels resultats destacats de la present recerca és el nivell de desigualat de gènere i de feminització de les tasques de cura de les persones en SDF a Barcelona. Les dades mostren que les dones representen pràcticament el $80 \%$ de les cuidadores principals de persones en SDF. Si bé en els casos de cuidadors familiars la diferència entre homes i dones és de 15 punts percentuals, quan es té en compte qui és la cuidadora principal la diferència es dispara (passa a 38 punts percentuals). Això suposa una càrrega de tasques que minva el benestar de moltes dones i de les seves trajectòries vitals (Sarasa i Mestres, 2007). Pel que fa a les persones cuidadores remunerades, tant a l'Administració pública com al mercat formal o informal, l'àmplia majoria són dones. En el cas de les que provenen del mercat formal i informal la gran majoria d'aquestes són d'origen estranger. En futures recerques seria convenient aprofundir en l'anàlisi dels perfils d'aquestes dones per saber elements com la seva forma de convivència i estructures de la llar, les seves trajectòries eductives, laborals o de mobilitat.

Més enllà de les desigualtats de gènere, els resultats també mostren desigualtats acumulatives. Segons les dades de l'EPSD, les llars que disposen de menys rendes són les que solen estar configurades per una persona sola, que en SDF fa que es pateixin més riscos per no tenir cobertes totes les necessitats. Com s'ha pogut veure, les persones que viuen soles tenen una menor probabilitat de rebre ajuda d'algun familiar, i si s'afegeix la manca de recursos econòmics, també tenen menys probabilitat de poder permetre's algun servei o ajut extern de pagament. Això fa que aquest perfil sigui altament vulnerable i dependent dels serveis que facilitin l'Administració pública. Tanmateix, les dades de cobertura de l'EPSD mostren que el temps que pot dedicar a la setmana el servei de SAD és molt menor del que dedica un familiar o persona cuidadora remunerada, 
la qual cosa fa que els perfils que en depenen com a principal font de cures pugui estar en una situació de major vulnerabilitat per manca de cobertura de les necessitats.

En aquest article s'han de tenir en compte algunes limitacions. La primera consideració, i que està vinculada al darrer punt tractat, és que a l'EPSD es consideren els ingressos de la llar de la persona i no altres formes de recursos econòmics que poden estar destinats a les cures. En ocasions, la despesa que pugui generar la contractació o el pagament d'un servei o persona cuidadora no respon tant a la persona en SDF, sinó als seus familiars que no conviuen amb ella. Tanmateix, tot i que els ingressos de la llar de la persona en ocasions no evidencia del tot els recursos econòmics que en pot disposar, les dades mostren diferències significatives en la probabilitat de recórrer a cures pagades entre els que tenen més recursos i els que en tenen menys. L'altra limitació d'aquest estudi és centrar-se en l'atenció de cures domiciliària en exclusiva que, si bé és la majoritària, seria interessant completar aquesta línia d'anàlisi introduint les residències i l'atenció als centres de dia.

La situació actual d'envelliment de la població fa que cada cop sigui més necessari abordar les necessitats que tenen les persones en SDF i les seves famílies per cobrir de forma efectiva les seves necessitats, i així minimitzar la incidència en el cost d'oportunitat i els possibles efectes lesius que puguin provocar en les cuidadores familiars. Com s'ha vist en els resultats d'aquest estudi, la majoria de persones en SDF són persones en edats avançades. Així doncs, és plausible que amb l'augment de la població en edats avançades creixi també la població en SDF. En aquest sentit, l'Estat del benestar i els serveis públics tenen el gran repte de donar resposta a aquestes necessitats creixents. No obstant això, el creixent envelliment de la població no s'ha de veure únicament com quelcom negatiu. Si bé suposa un gran repte en múltiples dimensions socials (pensions, serveis de cura, atenció sanitària, soledat, etc.) també es van donant avenços i millores tecnològiques, mèdiques o de mobilitat que permeten esmorteir els possibles impactes que puguin sorgir de la major proporció de persones amb edats avançades. Segons Sarasa i Mestres (2007), l'efecte de tenir una esperança de vida elevada s'hauria de veure més com un 
retard en l'aparició de malalties, problemes de salut o necessitats de cures que no tant un augment de la quantitat d'anys en SDF. Altres estudis també mostren una relació positiva entre viure més anys i gaudir-ne més amb bona salut (Mathers et alii, 2015).

En resum, aquest article mostra els perfils de les persones cuidadores i quines són les característiques de les persones en SDF que fan que rebin diferents suports per cobrir les seves necessitats de cura i d'ajuda a les activitats quotidianes. En aquest sentit emergeixen clars elements de desigualtats en què s'hauria de tenir especial atenció en les polítiques públiques. En primer lloc, les administracions públiques haurien de ser més determinants a l'hora de contribuir en la reducció de la dependència dels familiars en les tasques de cures, ja que pot suposar una situació de major vulnerabilitat per a les persones que no disposen d'aquests recursos relacionals, i perquè poden provocar un detriment dels projectes vitals dels familiars cuidadors. En aquest sentit, una major cobertura dels serveis públics pot contribuir a fer-los més atractius com a estratègies de cura. D'aquesta forma es podria reduir la càrrega de tasques als familiars i els possibles efectes negatius que se'n deriven, així com que les persones en SDF que viuen soles i no disposen de prou suport social, xarxa familiar o recursos econòmics tindrien les necessites més ben cobertes. En segon lloc, un altre eix d'intervenció hauria d'anar orientat a reduir la bretxa de gènere que existeix entre les persones cuidadores. Una reducció de l'atenció familiar suposaria una menor càrrega especialment per a les dones (que solen ser les principals responsables). Per altra banda, s'hauria d'incentivar la contractació de personal masculí per reduir la feminització de les tasques de cura a nivell professional. Això pot ser dificultós en el sector privat i en l'informal, però des de la contractació pública es podria arribar a potenciar incorporant requeriments en la contractació o en els plecs per licitacions d'empreses que vulguin oferir aquests serveis. Per altra banda, cal posar en valor les tasques de cura professionalitzades i millorar les seves condicions laborals d'acord amb l'exigència i la rellevància que tenen en el benestar de les persones en SDF. Aquests canvis es consideren elements cabdals per millorar les condicions de les persones cuidadores, i de retruc de les persones en SDF. 


\section{Referències}

Adams, B., Aranda, M. P., Kemp, B. i Takagi, K. (2002). «Ethnic and gender differences in distress among Anglo American, African American, Japanese American, and Mexican American spousal caregivers of persons with dementia». Journal of Clinical Geropsychology, 8(4): 279-301. Ayuso, M., Rubio, R. i Escribano, F. (2010). «Factores sociodemográficos y de salud asociados a la institucionalización de personas dependientes». Revista Española de Salud Pública, 84(6): 789-798.

BARKer, J. (2002). «Neighbors, Friends, and Other Nonkin Caregivers of Community-Living Dependent Elders». The Journals of Gerontology: Series B, 57, S158-S167.

Becker, G. S. (1993). «Nobel lecture: the economic way of looking at behavior». Journal of Political Economy, 101(3): 385-409.

Calvo, M. J. (2007). Distribució territorial de la renda familiar a Barcelona. Ajuntament de Barcelona.

Calzada, I., i Brooks, C. (2013). "The Myth of Mediterranean Familism: family values, family structure and public preferences for state intervention in care». European Societies, 15(4), 514-534.

CIS (2014). Cuidados a dependientes. Centro de Investigaciones Sociològicas, núm. 3009.

DALY, M., i LEWIS, J. (2000). "The concept of social care and the analysis of contemporary welfare states». The British journal of sociology, 51(2), 281-298.

Del Pozo Rubio, R. i Escribano Sotos, F. (2013). «Coste agregado e individual esperado de la Ley de Dependencia en España a partir de los modelos de simulación de Monte Carlo y Multi-Estado de Discapacidad». Hacienda Pública Española, 204(1), 85-110.

Del Pozo Rubio, R., Pardo García, I. i Escribano Sotos, F. (2016). «El copago de dependencia en España a partir de la reforma estructural de 2012 «. Gaceta Sanitaria, 31 (2017): 23-29.

Dié Olmos, L., Fantova, F. i Mota, R. (2014). Capital social y cultural en España. VII Informe sobre exclusión y desarrollo social en España 2014. Madrid: FOESSA. 
Eichler, M. i Pfau-Effinger, B. (2009). «The 'consumer principle' in the care of elderly people: free choice and actual choice in the German welfare State». Social Policy \&Administration, 43(6): 617-633.

Fernández-CARro, C. (2014). «Ageing at home, co-residence or institutionalisation? Preferred care and residential arrangements of older adults in Spain». Ageing and Society. 36(3): 586.

GANONG, L., i Coleman, M. (1999). Changing families, changing responsibilities: Family responsibilities following divorce and remarriage. Mahwah, NJ: Erlbaum.

Groenou, M. B., Glaser, K., Tomassini, C., i Jacobs, T. (2006). «Socioeconomic status differences in older people's use of informal and formal help: a comparison of four European countries». Ageing $\mathcal{E}$ Society, 26(5): 745-766.

Hillcoat-Nalletamby, S. (2019). «Pathways to choice'of care setting». Ageing \& Society, 39(2): 277-306.

Julià A. i RojAs, A. (2020). "La diversitat de la cura de les persones grans en situació de dependència funcional a Barcelona». Barcelona Societat, 25:42-57.

Katz, S. J., Kabeto, M., i Langa, K. M. (2000). «Gender disparities in the receipt of home care for elderly people with disability in the United States». Journal of the American Medical Association, 284(23): 3022-3027.

Larrañaga, I., Martín, U., Bacigalupe, A., Begiristáin, J. M., Valderrama, M. J. i ARREgI, B. (2008). «Impacto del cuidado informal en la salud y la calidad de vida de las personas cuidadoras: análisis de las desigualdades de género». Gaceta sanitaria, 22(5): 443-450.

Leitner, S. (2003). «Varieties of Familialism: The Caring Function of the Family in Comparative Perspective». European Societies, 5(4):353-375.

León, M. i Migliavacca, M. (2012): «Italy and Spain: Still the case of familistic welfare models?» A T. Martín García (ed.) Spain and Italy: As Similar as Thought? A comparative reflection on living arrangements and family relationships. Springer.

Martínez-Buján, R. (2014). «Los modelos territoriales de organización social del cuidado a personas mayores en los hogares». Revista Española de Investigaciones Sociológicas (REIS), 145(1): 99-124. 
Mathers, C. D., Stevens, G. A., Boerma, T., White, R. A. i Tobias, M. I. (2015). «Causes of international increases in older age life expectancy». The Lancet, 385(9967): 540-548.

Nolan, M., Grant, G. i KeAdy, J. (1996). Understanding family care: a multidimensional model of caring and coping. Buckingham: Open University Press.

Rogero, J. (2009). «La distribución en España del cuidado formal e informal a las personas de 65 y más años en situación de dependencia». Revista Española de Salud Pública, 83(3): 393-405.

SARACENO, C. (2010). «Social inequalities in facing old-age dependency: a bi-generational perspective». Journal of European Social Policy, 20(1): 3244 .

Sarasa, S. i Billingsley, S. (2008). «Personal and Household Care Giving from Adult Children to Parents and Social Stratification». A C. SARACEno (ed.) Families, Ageing and Social Policy. Cheltenham: Edward Elgar.

SARAsa, S. i Mestres, J. (2007). Women's employment and the adult caring burden. Family formation and family dilemmas in contemporary Europe. Madrid: Fundación BBVA. 